\title{
Quantitative analysis of expression patterns of different cell surface Toll-like receptor genes imparting heat stress resilience to indigenous Osmanabadi and Salem Black goat breeds
}

\author{
Sira Tulasiramu Savitha • Venkataswamy Girish Kumar • Veettiparambil Pandarathil Rashamol • Veerasamy Sejian iD. \\ Madiajagan Bagath • Govindan Krishnan - Chinnasamy Devaraj • Raghavendra Bhatta
}

\section{ST Savitha ${ }^{A, B}$ - VG Kumar ${ }^{B}$ - VP $\operatorname{Rashamol}^{\mathrm{A}}$ - V Sejian ${ }^{\mathrm{A}}$ (Corresponding author) - M Bagath ${ }^{A}$ - G Krishnan ${ }^{\mathbf{A}}$ - C Devaraj $^{\mathrm{A}}$ - R Bhatta ${ }^{\mathrm{A}}$}

email: drsejian@gmail.com
ACAR-National Institute of Animal Nutrition and Physiology, Adugodi, Hosur Road, Bangalore-560030, Karnataka, India.

${ }^{B}$ Veterinary College, Karnataka Veterinary Animal and Fisheries Sciences University, Hebbal, Bangalore-560024, India.

Received: August 22, 2019 • Accepted: September 11, 2019 • Published Online: September 27, 2019

\begin{abstract}
The study was conducted to establish the differences in the expression pattern of different cell surface toll-likereceptors (TLRS) between indigenous Osmanabadi and Salem Black goats subjected to summer season induced heat stress. The primary objective of the study is to assess the thermotolerance ability of these two breeds based on maintaining the immune status during exposure to heat stress. The results indicated that the expression of TLR1, TLR4, TLR5, TLR6, and $T L R 10$ genes in both the breeds showed different expression pattern. The expression pattern of all these genes did not differed between the control (OC) and heat stress (OHS) group in Osmanabadi breed but significantly higher $(\mathrm{P}<0.05)$ expression of these genes were reported in heat stress group (SBHS) as compared to control group (SBC) in Salem Black breed. However, the striking difference was established in the expression pattern of TLR2 between these breeds. The TLR expression was significantly higher in heat stress group of Osmanabadi breed. But TLR2 did not express in Salem Back breed. The higher expression of most of the cell surface TLRS in the SBHS group as compared to OHS group indicates the superior resilient capacity of Salem Black goats to maintain immune status even during exposure to adverse environmental condition. Further, these TLRS could serve as indicators to reflect better thermo-tolerance of Salem Black breed over Osmanabadi breed.
\end{abstract}

Keywords: caprine, immune response, thermal stress, THI, thermo-tolerance, $T L R$

\section{Introduction}

Heat waves are extreme meteorological event in the changing climate scenario causing extreme heat stress which affects severely the welfare of the animals (Bernabucci and Mele 2014; Rashamol et al 2018). Particularly, heat stress has a negative influence on farm animal productivity and health because of the presence of close relationship between metabolic heat generation and production level (Bernabucci et al 2010; Chaidanya et al 2017).

Among the domesticated ruminant species, the goat has been projected as the ideal animal that can withstand the detrimental effects of climate change (Silanikove 2000). Among the various environmental stressors, heat stress is the major stressor that affects the immune response in the goats (Sophia et al 2016). Goats adapt better to the changing climate compared to other ruminant livestock species. This is attributed to their better browsing capability with their anatomical advantage of upper lips and their ability to survive with less feedstuff in harsh climatic conditions in arid and semi-arid regions. Moreover, they have the ability to thrive very well in different agro-ecological zones. In addition, because of the specialty in the browsing of feed, they possess better water conservation ability than other ruminant animals.

The tropical environments in developing countries possess sound animal genetic resources to withstand the climatic extremes (Madhusoodan et al 2019). However, over the last few decades, the indigenous germplasms are depleting particularly in the developing countries due to genetic erosion (Belew et al 2016). Indigenous breeds were established to have resistance capacity of various degrees to withstand high ambient temperature under tropical environmental conditions (Rashid et al 2013). Therefore, indigenous livestock can be projected as future animals to ensure food security under changing climate scenario (Katiyatiya et al 2017). Hence, research efforts are needed to identify suitable indigenous livestock breeds, which have the ability to survive in different agro-ecological zone.

Generally, heat stress negatively affects humoral and cell-mediated immunity ( $\mathrm{Jin}$ et al 2011). Toll-like receptors 
are one of the pattern recognition receptors (PRRs) which are found in serum, on the cell surface, in endosomes and in the cytoplasm (Medzhitov 2001). These TLRs are expressed on variety of immune cells such as dendritic cells (DCs), natural killer (NK) cells, T cells, and B cells (Chen and Yu 2016). They recognize the pathogen-associated molecular pattern (PAMPs), which are expressed by the pathogens and dangerassociated molecular patterns (DAMPs), which are the components of damaged or apoptosed cells that act as endogenous stress signals (Vidya et al 2016). Moreover, the presence of these TLRs in organs and their expression pattern in response to specific stimuli is one of the factors determining the disease resistance capability of an animal (Tirumurugaan et al. 2010). Further, Paul et al (2015) suggest that goats under heat-stressed state showed significant up-regulation of few $T L R s$ which play an important role in stimulating the innate immune response.

Currently, sufficient research reports are available pertaining to establishing the impact of heat stress on both adaptation and production. However, such reports establishing heat stress impact on immune status particularly in the indigenous livestock population are very limited. Therefore, a study was designed in two different indigenous Osmanabadi and Salem Black goat breeds to comparatively assess their resilience capacity to heat stress based on their ability to maintain their immune status during exposure to adverse environmental condition. The primary objective of the study was to establish the impact of heat stress on the different cell surface Toll-Like-Receptor expression pattern between these two breeds.

\section{Materials and Methods}

The Osmanabadi breed has its origin from the study locality while Salem Black breed was brought from the other agro-ecological zone to the current study location to compare the adaptive potential of this breed to the native track Osmanabadi breed. The study was conducted for a period of 45 days in twenty-four one-year-old female Osmanabadi and Salem Black breed goats. The animals were randomly allocated into four groups of six animals each, OC $(n=6$; Osmanabadi control) and OHS ( $n=6$; Osmanabadi heat stress). SBC ( $\mathrm{n}=6$; Salem Black control) and SBHS ( $\mathrm{n}=6$; Salem Black heat stress). Both OC and SBC animals were maintained in the shed in comfort condition while OHS and SBHS animals were exposed outside to summer heat stress between 10:00 to 16:00 during the experimental period. The average environmental variables were described in Table 1.

Table 1 Description of microclimate (environmental variables) during the study.

\begin{tabular}{|c|c|c|c|c|}
\hline \multirow{3}{*}{ Environmental Variables } & \multicolumn{4}{|c|}{ Mean } \\
\hline & \multicolumn{2}{|c|}{ Inside Shed } & \multicolumn{2}{|c|}{ Outside Shed } \\
\hline & Forenoon $(8: 00)$ & Afternoon (14:00) & Forenoon $(8: 00)$ & Afternoon (14:00) \\
\hline Air Temperature $\left({ }^{\circ} \mathrm{C}\right)$ & $26.6 \pm 0.31$ & $34.2 \pm 0.22$ & $28.8 \pm 0.61$ & $39.9 \pm 0.63$ \\
\hline Relative Humidity (\%) & $56.7 \pm 1.76$ & $37.1 \pm 1.62$ & $58.6 \pm 2.54$ & $29.1 \pm 1.75$ \\
\hline Pen Surface Temperature $\left({ }^{\circ} \mathrm{C}\right)$ & $25.5 \pm 0.20$ & $30.6 \pm 0.46$ & $29.5 \pm 0.61$ & $47.4 \pm 0.76$ \\
\hline Temperature-Humidity-Index & $69.9 \pm 0.16$ & $74.9 \pm 0.14$ & $73.5 \pm 0.56$ & $86.5 \pm 0.39$ \\
\hline
\end{tabular}

The THI values for the study duration were calculated as per the method described by McDowell (1972). The animals were slaughtered at the end of the study and their mesenteric lymph node (MLN) samples were collected for assessing the different toll-like receptor genes. The targeted genes were TLR1, TLR2, TLR4, TLR5, TLR6 and TLR10 genes. The relative expressions of selected genes were studied using SYBR green chemistry after designing appropriate primers for the target genes. The glyceraldehyde 3-phosphate dehydrogenase $(G A P D H), \quad$ Hypoxanthine phosphoribosyltransferase 1 (HPRT1), and Succinate dehydrogenase complex flavoprotein subunit A (SDHA), genes were used as reference genes and the relative expression of all target genes were analyzed using the formula $2 \Delta \Delta \mathrm{CT}$. All animal procedures were approved by the Institute Ethical Committee for subjecting the animals to heat stress, ICARNIANP, India (NIANP/IAEC/2/2017). The quantitative relative expression pattern between target genes and housekeeping genes were analyzed by paired t-test using SPSS software (version 18.0). The level of statistical significance was set at $\mathrm{P}<0.05$. 


\section{Results}

The THI values for the entire study duration during the morning were not stressful to the animals kept both inside and outside the shed. However, the obtained THI values $(\mathrm{P}<0.01)$ during the afternoon indicated that the animals inside the shed were not stressed while the animals kept outside the shed were under extreme distress. The expression patterns of different cell surface TLRs are described in Figure 1. The fold changes of expression patterns of TLR1 gene between control and heat stress groups of Osmanabadi and Salem Black breeds are 1.0, 1.1 and 1.0, 2.2, respectively (Figure 1a). The expression patterns of TLR1 gene did not differ in Osmanabadi breed while significantly $(\mathrm{P}<0.01)$ up-regulated in SBHS group as compared to rest all groups (OC, OHS and SBC). The fold changes of expression patterns of TLR 2 gene between control and heat stress groups of Osmanabadi breed are 1.0 and 5.2, respectively (Figure 1b). However, TLR2 did not get expressed in the Salem Black breed while significantly higher expression was recorded in OHS group as compared to OC group. The fold changes of expression patterns of TLR4 gene between control and heat stress groups of Osmanabadi and Salem Black breeds are 1.0, 0.9 and 1.0, 4.5, respectively
(Figure 1c). The expression patterns of TLR4 gene significantly $(\mathrm{P}<0.01)$ up-regulated in SBHS group as compared to rest all groups (OC, OHS and SBC). Likewise, the expression pattern of TLR5 gene also significantly $(\mathrm{P}<0.01)$ up-regulated in SBHS group as compared to SBC group animals. The fold changes of expression patterns of TLR5 gene between control and heat stress groups of Osmanabadi and Salem Black breeds are 1.0, 0.8 and 1.0, 3.9, respectively (Figure 1d). In addition, the expression pattern of TLR6 gene also was significantly $(\mathrm{P}<0.01)$ up-regulated in SBHS group as compared to rest all groups (OC, OHS and SBC). The fold changes of expression patterns of TLR6 gene between control and heat stress groups of Osmanabadi and Salem Black breeds are 1.0, 0.9 and 1.0, 2.3, respectively (Figure 1e). Furthermore, TLR10 expression pattern also showed similar trend of up-regulation $(\mathrm{P}<0.01)$ as that of other cell surface TLRs studied in SBHS group as compared to rest all groups (OC, OHS and $\mathrm{SBC}$ ). The fold changes of expression patterns of TLR 10 gene between control and heat stress groups of Osmanabadi and Salem Black breeds are 1.0, 0.9 and 1.0, 3.5, respectively (Figure 1f).
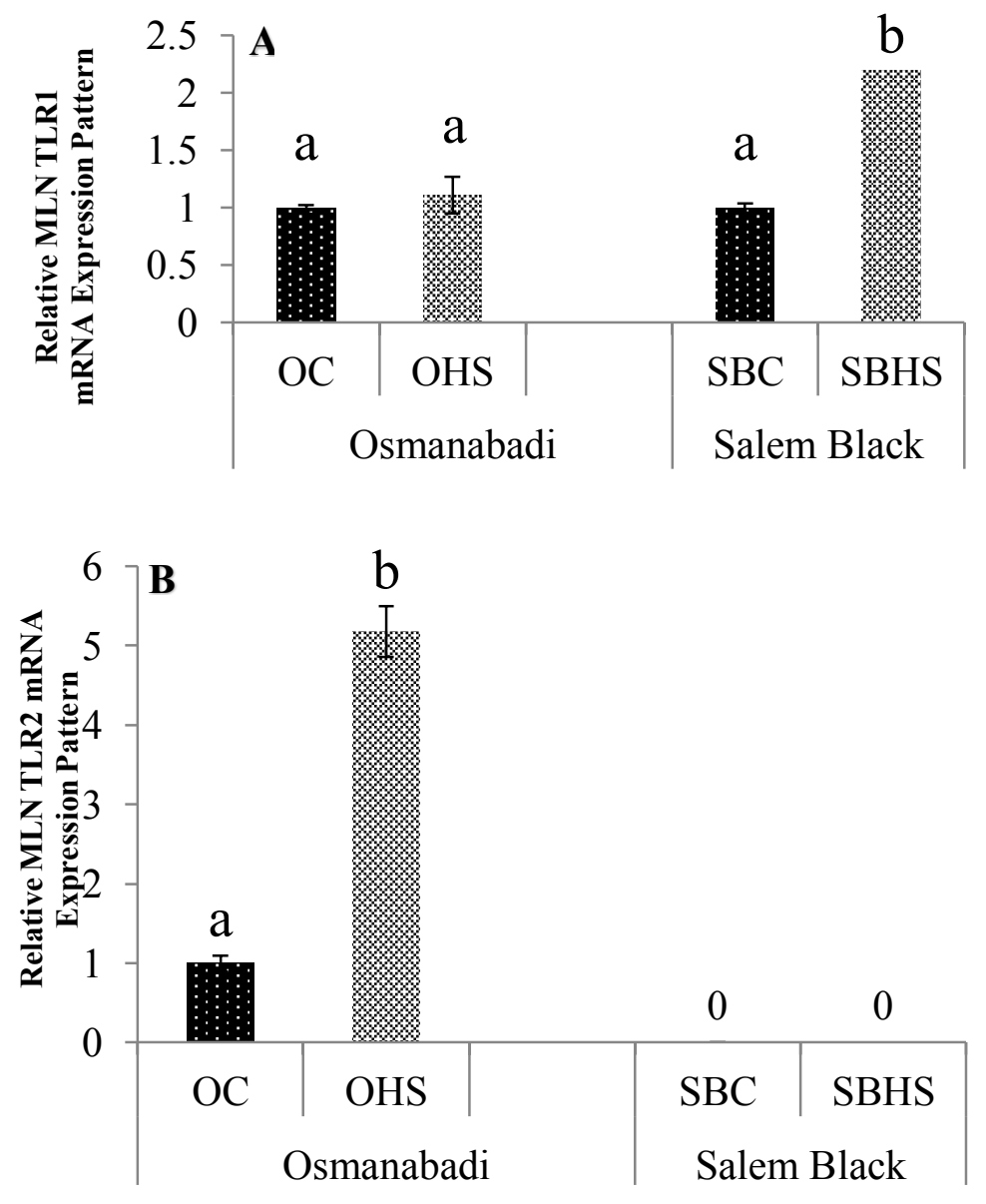

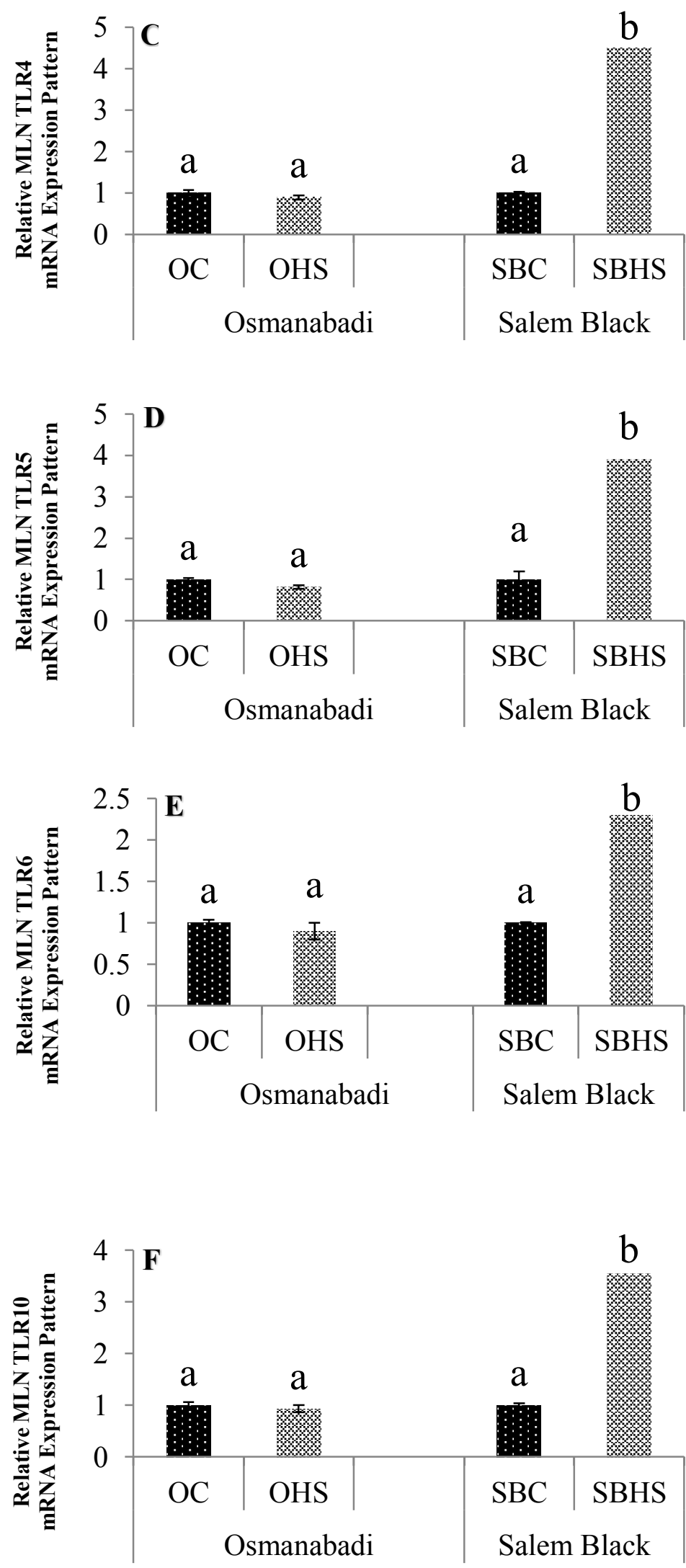

Figure 1 Expression pattern of different cell surface toll-like-receptor gene expression in MLN of both Osmanabadi and Salem Black goat breeds. OC- Osmanabadi Control; OHS- Osmanabadi Heat Stress; SBC-Salem Black Control; SBHS-Salem Black Heat Stress; MLNMesenteric Lymph Node; TLR-Toll-Like Receptor. The various target genes were: TLR1 (Figure 1a); TLR2 (Figure 1b); TLR4 (Figure 1c); TLR5 (Figure 1d); TLR6 Figure 1e); TLR10 (Figure 1f). The values bearing different superscripts differ with each other at $\mathrm{P}<0.05$. 


\section{Discussion}

The study is the first of its kind to assess the thermotolerance of two different indigenous goat breeds based on immune system-related gene expression patterns. The study was of practical relevance as the global community is working towards improving the resilience capacity of indigenous breeds to climate change and sustaining their production to ensure food security by 2050 . It is also very essential to identify a breed with better immune competency which may impart disease resistance capacity to cope with the sudden outbreak of diseases emerging as a result of climate change. In this line, the results of this study may give valuable clue about choosing the best breed which has the ability to survive in different agro-ecological zone.

Similar to our finding, Paul et al (2015) also reported significantly higher TLRl expression during exposure to summer season induced heat stress in Black Bengal goats. Further, Tirumurugaan et al (2010) also reported increased expression of TLR1 in different organs such as uterus, skin, lymph node, PBMC, and lungs of heatstressed Kanni breed goats. These breeds are also indigenous in nature with good disease resistance capacity in their respective region of origin. Therefore, the increased expression pattern of TLR1 in Salem Black goats could be due to the sustained efforts of these animals to maintain the immune status. Tirumurugan et al (2010) explained that the increased expression of TLR1 in lymph nodes of the gastro-intestinal tract could be due to the constant activation by antigens. The non-significant effect of heat stress on TLRI expression in Osmanabadi breed could be attributed to the fact that the study location was the native track of this breed. Among the cell surface TLRS only TLR2 was up-regulated in Osmanabadi breed. This indicates the functional significance of this TLR in imparting immune competency to Osmanabadi breed. However, TLR2 did not express at all in Salem Black breed. This indicates the breed difference in the expression pattern of TLR2 in goats.

Among the TLRs, TLR4 was established to be associated with the damage-associated molecular patterns (DAMPs) to induce immune response during heat stress by producing pro-inflammatory cytokines (Bharati et al 2017). Like TLR1, TLR4 also showed similar expression pattern between the breeds with no difference between the groups in Osmanabadi breed and significantly higher expression of TLR4 recorded in SBHS group of Salem Black breed. However, contrasting report of significantly lower TLR4 expression pattern was recorded in other indigenous goat breeds such as Malabari (Vandana et al 2018) and Osmanabadi goats (Sophia et al 2016). These findings suggest the superiority of Salem Black breed to maintain immune status as compared to even other indigenous goat breeds. Similar to our findings there are also reports of higher expression of TLR4 in response to heat stress in different species (Ju et al 2014; Paul et al 2015; Bharati et al 2017). This difference between these studies could be attributed to the difference in the magnitude of heat stress as well as the difference in the adaptive capacity of different breeds.

Similar to the trends of TLR1 and TLR4, TLR5 also showed the same expression pattern between the breeds with no difference between the groups in Osmanabadi breed and significantly higher expression of TLR4 recorded in SBHS Salem Black breed. In a similar study in our laboratory, Vandana et al (2018) reported significantly lower expression of TLR 5 and they attributed this to the lower thermo-tolerance ability of the Malabari goats. The non-significant influence of heat stress on TLR5 expression in Osmanabadi breed suggests an ability to withstand heat stress but the significantly higher expression of TLR5 in Salem Black breed indicates the ability of this breed to mount appropriate immune response even during exposure to adverse environmental condition. Similar to the no effect of heat stress in female Osmanabadi goats in the current study was similar to the findings reported by Sophia, et al (2016) in male Osmanabadi breed.

The expression pattern of TLR6 also was similar to that of TLR1, TLR4, and TLR5 in the current study. Similar results of significantly higher TLR6 expression pattern were also reported in other species (Plain et al 2010; Paul et al 2015; Srikanth et al 2017). These authors attributed this to the superior thermo-tolerance of these animals. Hence the similar finding in Salem Black breed could be attributed to the climate resilient capacity of this breed. This argument was supported by the findings of Aleena et al (2018) who established superior thermo-tolerance of Salem Black breed over other two indigenous Osmanabadi and Malabari breeds when exposed to heat stress. The non-significant influence of heat stress on TLR6 expression pattern in Osmanabadi breed could be attributed to the origin of this particular breed to the study location. Quantitative expression pattern of TLR10 also followed the same pattern as that of TLR1, TLR4, TLR5, and TLR6. Similar findings of no effect of heat stress on TLR10 expression pattern also was established by Vandana et al (2018) and Sophia et al (2016) in Malabari and Osmanabadi breeds respectively. In contrast to these findings, significantly higher TLR10 expression was reported in the heat stress group of Salem Black breed. Similar to this finding on TLR10 expression in Salem Black breed, Paul et al (2015) also established significant up-regulation of TLR10 in Black Bengal goats during exposure to heat stress. This finding again supports the argument of superior thermo-tolerance of Salem Black breed over Osmanabadi breed in maintaining the immune status during exposure to hot and humid tropical environmental conditions.

The results indicated that Salem Black breed possessed superior ability to maintain the immune response even during exposure to extreme climatic conditions. This is evident from the significant up-regulation of TLR1, TLR4, TLR5, TLR6, and 
TLR10 in heat stress groups of this breed as compared to control group reflecting that the animals were able to mount appropriate immune response during exposure to extremely severe heat stress. The result points towards the excellent resilience capacity of Salem Black breed to heat stress challenges. This was evident from their ability to maintain superior immune status by up-regulating all cell surface TLRs during exposure to adverse environmental condition.

\section{Conclusions}

The study indicated that TLR1, TLR4, TLR5, TLR6, and $T L R 10$ significantly up-regulated in SBHS group as compared to the OHS group. The higher expression of most of the cell surface TLRS in the SBHS group indicates the superior resilient capacity of Salem Black goats as compared to Osmanabadi breed to maintain immune status even during exposure to adverse environmental condition. Further, the non-significant influence of heat stress on the majority of TLRS studied in Osmanabadi breed indicates the indigenous nature of this breed to cope with the existing climatic condition of its origin. In addition, the significantly higher expression of TLR1, TLR4, TLR5, TLR6, and TLR10 in the heat stress group indicates the reliability of these genes to act as biological markers for assessing the immune status of Salem Black breed during heat stress exposure.

\section{Acknowledgements}

The authors are also highly thankful to the Director, ICAR-National Institute of Animal Nutrition and Physiology for providing the research facilities to complete the experiment.

\section{Conflict of Interest Statement}

We confirm that we have no conflicts of interest.

\section{References}

Aleena J, Sejian V, Bagath M, Krishnan G, Beena V, Bhatta R (2018) Resilience of three indigenous goat breeds to heat stress based on phenotypic traits and PBMC HSP70 expression. International Journal of Biometeorology 62:1995-2005.

Belew AK, Tesfaye K, Belay G, Assefa G (2016) The State of Conservation of Animal Genetic Resources in Developing Countries: A Review. International Journal of Pharma and Bio Sciences 5:58.

Bernabucci U, Mele M (2014) Effect of heat stress on animal production and welfare: The case of a dairy cow. Agrochimica 58:5360.

Bernabucci U, Lacetera N, Baumgard LH, Rhoads RP, Ronchi B, Nardone A (2010) Metabolic and hormonal acclimation to heat stress in domesticated ruminants. Animal 4:1167-1183.

Bharati J, Dangi SS, Mishra SR, Chouhan VS, Verma V, Shankar O, Bharti MK, Paul A, Mahato DK, Rajesh G (2017) Expression analysis of Toll like receptors and interleukins in Tharparkar cattle during acclimation to heat stress exposure. Journal of Thermal Biology 65:48-56.

Chaidanya K, Soren, NM, Sejian V, Bagath M, Manjunathareddy GB, Kurien EK, Varma G, Bhatta R (2017) Impact of heat stress, nutritional stress and combined (heat and nutritional) stresses on rumen associated fermentation characteristics, histopathology and HSP70 gene expression in goats. Journal of Animal Behaviour and Biometeorology 5:36-48.

Chen L, Yu J (2016) Modulation of Toll-like receptor signaling in innate immunity by natural products. International Immunopharmacology 37:65-70.

Jin Y, Hu Y, Han D, Wang M (2011) Chronic heat stress weakened the innate immunity and increased the virulence of highly pathogenic avian influenza virus $\mathrm{H} 5 \mathrm{~N} 1$ in mice. BioMed Research International 29:367846.

Ju XH, Xu HJ, Yong YH, An LL, Jiao PR, Liao M (2014) Heat stress upregulation of toll-like receptors $2 / 4$ and acute inflammatory cytokines in peripheral blood mononuclear cell (PBMC) of Bama miniature pigs: an in vivo and in vitro study. Animal 8:1462-1468.

Katiyatiya C L F, Bradley G, Muchenje V (2017) Thermotolerance, health profile and cellular expression of HSP90AB1 in Nguni and Boran cows raised on natural pastures under tropical conditions. Journal of Thermal Biology 69:85-94.

Madhusoodan AP, Sejian V, Rashamol VP, Savitha ST, Bagath M, Krishnan G, Bhatta R (2019) Resilient Capacity of Cattle to Environmental Challenges - An Updated Review. Journal of Animal Behaviour and Biometeorology 7:104-118.

McDowell RE (1972) Improvement of livestock production in warm climate. 1. WH Freeman \& Co. San Francisco, U.S.A.

Medzhitov R (2001) Toll-like receptors and innate immunity. Nature Reviews Immunology 1:135-145.

Paul A, Dangi SS, Gupta M, Singh J, Thakur N, Naskar S, Nanda PK, Mohanty N, Das A. K, Bandopadhayay S (2015) Expression of TLR genes in Black Bengal goat (Capra hircus) during different seasons. Small Ruminant Research 124:17-23.

Plain KM, Purdie AC, Begg DJ, de Silva K, Whittington RJ (2010) Toll-like receptor (TLR) 6 and TLR1 differentiation in gene expression studies of Johne's disease. Veterinary Immunology and Immunopathology 137:142-148.

Rashamol VP, Sejian V, Bagath M, Krishnan G, Archana PR, Bhatta R (2018) Physiological adaptability of livestock to heat Stress: an updated review. Journal of Animal Behaviour and Biometeorology 6:62-71.

Rashid MM, Hossain MM, Azad MA, Hashem MA (2013) Long term cyclic heat stress influences physiological responses and blood characteristics in indigenous sheep. Bangladesh Journal of Animal Science 42:96-100.

Silanikove N (2000) Effects of heat stress on the welfare of extensively managed domestic ruminants. Livestock Production Science $67: 1-8$

Sophia I, Sejian V, Bagath M, Bhatta R (2016) Quantitative expression of hepatic toll-like receptors 1-10 mRNA in Osmanabadi goats during different climatic stresses. Small Ruminant Research 141:11-16.

Srikanth K, Kwon A, Lee E, Chung H (2017) Characterization of genes and pathways that respond to heat stress in Holstein calves through transcriptome analysis. Cell Stress Chaperones 22:29-42. 
Tirumurugaan KG, Dhanasekaran S, Raj GD, Raja A, Kumanan K, Ramaswamy V (2010) Differential expression of toll-like receptor mRNA in selected tissues of goat (Capra hircus). Veterinary Immunology and Immunopathology 133:296-301.

Vandana GD, Bagath M, Sejian V, Krishnan G, Beena V, Bhatta R (2018) Summer season induced heat stress impact on the expression patterns of different toll-like receptor genes in Malabari goats. Biological Rhythm Research 18:1-7.
Vidya MK, Kumar VG, Sejian V, Bagath M, Krishnan G, Bhatta R (2018) Toll-like receptors: significance, ligands, signaling pathways, and functions in mammals. International Reviews of Immunology 37:20-36. 